\title{
Value Added Tax between Reality \& Ambition
}

\author{
Ali M. Shahin Sangor \\ University Al-Furat Al-Awsat Technical \\ Technical Institute of Samawah \\ Assistant Lecturer / Department of Accounting
}

\begin{abstract}
The Increasing attention of governments in different systems of governance and political ideas which it believes, as policy tools Finance, is seeking to achieve through which the objectives of economic, social and political settlement is not about financial goals, as the policy Tax formulated goals consistently and harmony with the objectives of economic policy in general, have resorted to various countries in the framework of Tax reform to search for possible alternatives to keep the tax policy effective financially, economically and socially, Iraq should not be different from these countries and draws a consistent tax policy and future conditions data .Within the context of this research deals with the subject of the value added tax, because of their importance to the Iraqi economy in Now a day, the increasing incidence of side applied by many countries of the world from the other side.

The research consists of two sections, was addressed in the first section of it to the theoretical framework for value-added tax in terms of the Concept and the basic features and advantages to them, as well as the application of in different countries of the world, as well as how calculated and Registration Its accounting, while the second section guarantees the first axis to clarify the procedures that can be adopted in the possibility of imposing VAT in Iraq, while the second axis has included the analysis of the results of the questionnaire to a number of academics and specialists in the tax field, the research found, among other conclusions and make appropriate recommendations to them.
\end{abstract}

\section{Introduction}

Pending edits shown on this page is checked. VAT is multiplicative vehicle imposes on the difference in the cost price and the selling price of goods, it is a tax on the cost of production, and arguably the VAT is an indirect tax first appeared in 1954 in France thanks to Morris Loret which put its main bases in 1953, the average tax rate was $20 \%$ with increases of up to $23 \%$ and $25 \%$, as they include low rates of up to 6 and $10 \%$.

The multiple and intersecting variables experienced by the Iraq economy in general, and the tax system specifically, Require substantial modifications in the tax legislation in force in Iraq, with the shape that makes the tax system in Iraq is in line with procedures accommodate the global and local variables, like the different tax systems .

It has resorted to various countries in the context of tax reform to search for possible alternatives to keep the tax policy Effective protective Stadia financially and socially, and Iraq should not be different from these countries and draws a consistent tax policy Data and future conditions.

In light of what is produced by the variables mentioned above, it is possible to bring about changes in the tax structure adoption Tax with Allay achieve the objectives of the Mechanism, economic and social, and in the introduction of this tax, the most important of VAT.(8)

Value Added Tax added the spread of the VAT, the most important developments in the last fifty years in its field in the tax, in the fifties of the last century did not hear this tax differed outside France, but now it is implemented in 139 countries, where contribute usually including nearly a quarter of the total tax revenue, and moreover there is still a lot of work in the field of serious tax Value-added, and is still the number of countries that support this tax is growing, but the countries that are already adopted term Strives to improve the design, implementation, and experience problems are similar in many aspects across different countries, such as how to Tax refund and the problems of fraud and tax evasion.(9)

\section{Problem Statement}

The research problem is the design and implementation of VAT in Iraq, the difficulty of the opinion of dealing with fiscal policy, in spite of its importance in the financing of the state treasury more than that enhance revenue and let Iraqi economy, particularly at the present time, which is witnessing a decline in oil prices.

\section{Research Significance}

Perhaps the concerns of Iraq's internal various kinds loosen a shadow on the entire interest in the official, who did not preclude consideration Comprehensiveness of other topics related to the location of vital 
regional and interaction with various countries and economic organizations International, and the expected effects on the regime and the activity of these blocs, which seems to be acceding to stay away from them or him Risks in both cases.

In this sense, the importance of this research to clarify the procedures by which it can impose VAT Iraq, and that the introduction of the tax this means re-examining its tax system in Iraq any restructuring of the tax base.

In order to update the system and increase its effectiveness, and moreover, this step is an important character wears depending on developments the current global economy.

\section{Research Objectives}

This research seeks to achieve a number of objectives can be summarized as follows:

1 - Review of the theoretical framework for the VAT.

2 - To address the features and history of the application of VAT in different countries of the world.

3 - To clarify the mechanism and method of calculating the value-added tax, as well as the accounting treatment of her.

4 - Review of the procedures by which to enforce and implement the VAT in Iraq.

5 - To discuss obstacles to the application of the VAT system in Iraq.

\section{Research Hypothesis}

Search is built on the premise of the following there is significant correlation between the imposition of tax and increase state revenues by more than the cost in the case of debts the existence of effective management procedures based on efficient imposition and collection adoption of the accounting records and in the framework of good awareness of tax.

\section{The Concept Of Value-Added Tax}

VAT is a tax levied on the increase in the value of goods and services at each stage of Production and circulation, and looks at her from the other side as a tax on consumption is met at every stage of the session Economic, and applied in accordance with the amount of consumption, in other words, caused. The value paid by touching perishes in order to get Funds or services. (1)

Of course, the imposition of a tax on final goods may mean the imposition of tax on the item per respondent several times during the stages Posed, and to avoid these risks, the tax levied on the various stages of production in order to ensure non-recurrence of taxation, Under this tax imposed upon the output tax at each stage of production, regardless of use For this product, and to ensure that the imposition of the tax on final consumption, the tax on all goods and services that have been used As inputs in the production process should be returned to those who have purchased these goods .(2)

The tax applies to all stages of production, but do not infect only the value added to the value of production, Tax levied on the difference between the price at which it sold goods and services produced and the cost of production employed by. Used in the production of these goods and services and in every stage of production.

\section{Literature Review}

The VAT, first introduced in Ghana in March 1995, was intended to overcome the problems in the existing sales tax system - such as narrow base, weak administration, and corruption-prone physical surveillance (3). The VAT rate was set at 17.5 percent, significantly higher than the standard rate of 15 percent applied in the replaced sales tax. A new revenue collection agency, the VAT Service, was established (13). A computer system was developed. However, the VAT was short-lived: It was removed just three and a half months after its introduction. The failure was due to multiple problems rooted in the tax policy design, timing, and implementation .

The high introductory VAT rate did not make the VAT politically acceptable. The timing of the VAT introduction was bad, and it actually fueled the civil unrest: its introduction coincided with several factors that were beyond the scope of the VAT and put upward pressure on inflation (e.g., agricultural prices were sharply increased due to unfavorable rainfall; the excise duty on petroleum products was also raised). In addition, the lack of preparation made the VAT doomed to fail-the VAT was actually launched only about three months after the primary VAT legislation was passed in December 1994. The conflict between the newly established VAT Service, and the Customs, Excise and Preventive Service (CEPS) was acute and eventually led to significant delays in the appointment of senior staff to the VAT Service and transfer of staff from the CEPS to the VAT Service. (The CEPS initially believed it would be responsible for administering the VAT; but in the end, it was resented that the charge was handed over to the VAT Service.) The threshold was set too low (25 million Cedi or $\$ 15,000$ ), while the public education failed to reach small traders and consumers. (14) 
The VAT was reintroduced in 1998. This time, the reformers learned well the lessons from the 1995 failed attempt. The legislation was enacted 10 months prior to the adoption of the VAT - this gave sufficient time to train and recruit capable staff for the VAT Service and to prepare the public form the tax. The rate was introduced at a substantially lower level (10 percent). In addition, many basic goods such as unprocessed food, agricultural inputs and machinery, drugs and health services, utilities, books, and educational materials were exempted to quench the initial public anxiety. The threshold was raised sharply to 200 million Cedi $(\$ 80,000)$ - it should also be emphasized that the country has recently halved the threshold, to 100 million Cedi. The VAT was successful: from the first year after introduction, the VAT generated 20 percent more revenues than the replaced sales tax. After less than 2 years, the government raised the rate to 12.5 percent, but maintained the reduced rate of 10 percent for imports subject to VAT. It is currently planning to broaden the base by reducing the number of exemptions. (14)

The VAT is a tax prior to use modern and indirect taxes were imposed at certain goods Chalkier, alcoholic beverages and taxes on retail sales, I grew VAT initially to meet the growing needs of the revenue that cannot be met easily by taxes on turnover ,Due to their nature that result in severe deformity economic decisions has slowly began to adopt VAT. This has helped the adoption of value-added tax as a condition for membership in the European Union on the spread of this tax in countries in that region (including non-member countries such as Norway and Switzerland). (15)

This tax has been adopted now in all member countries of the Organization for Economic Cooperation and Development (OECD) with the exception of the United States the nineties witnessed a boom in the area and the rate of adoption of VAT in all countries of the economic transformation almost this reflects the need to change the traditional sources of revenue.(15)

In spite of that the application of VAT did not begin until about 50 years ago, but this tax has become a source President of the revenues in the majority of countries in the world, and constitute a value-added tax is now about a quarter of tax revenue, and Approximately 5\% of the total GDP, among the 184 member states of both organizations (IMF and the World Bank), the 127 countries which represents $69 \%$ of all them apply VAT, and this includes all states most of the European countries, the Americas and most of the Asian countries, and almost half of the countries in the African continent and almost all state which was the socialist camp. But they, like other Arab countries of the developing countries followed the value-added tax as a component of the reform the policy to support the state budget, after that reduced dependence on resources such as grants and enter oil revenues, and there are currently eight countries apply VAT (Algeria, Egypt, Morocco, Tunisia, Lebanon, Jordan, Palestine, Mauritania). And trying these countries and in the context of tax reform to apply VAT to achieve the objectives of the phrase, including increased General tax revenues and a willingness to reduce dependence on customs taxes, which constitute a significant proportion of the total Tax revenue, after growing calls for the liberalization of trade and the establishment of free trade zones.(16)

As in Iraq, what can be seen initially, that the application of VAT is not without problems of Different dimensions that may impede the imposition of such a tax, including lack of awareness of the tax, and the proliferation of images and various aspects of its Evasion and tax avoidance, and do not reflect the national dimension of the tax in an integrated manner, in addition to the different problems each the ability of accounting applications to find solutions to the problems expected in this area, as well as with regard to applications Tax, and specifically in the field of audit and examination adhere me, in addition, the problems related to the economy. Iraqi general and the resulting relationship between the local governments in the provinces and territories with the central government, will be To address this in detail later.(17)

\section{Advantages Of Vat}

Advocates marketed to value-added tax and supporters have many advantages achieved when imposing this type of taxes, and most important of these advantages:

To make domestic producers and foreign enterprises doing business in Iraq more competitive on international markets. To make the system an effective means of collection of indirect taxes and stable and effective source of government revenue. VAT removes the tax on exports, the basic bookkeeping required for vat provides a basis for more efficient business practices and in many instances improves profitability.(18)

Stocks of goods are held free of vat which facilitates the development of businesses. The inefficient vat system provides the basis for efficient tax administration and addresses the shadow economy. The value-added tax levied on the various stages of production, where it is offset taxes Input from taxes on products or outputs, this means that sellers are required to impose Taxes on all their sales, at the same time they can claim compensation for the taxes that were imposed on them in the goods which they used as inputs in a puppet production, so that the feature has become a revenue Amador forth through Collected during all production processes, on the contrary, from taxes on retail sales, and that this type of Taxes do not distort production decisions, as is the case in the final tax on the income.(19) 
The value-added tax neutral because it does not limit the pay a tax on a certain stage of production, as well as they help to promote exports, because this usually does not impose a tax on exports.

Advantages also said that the tax burden borne by domestic goods be equal or comparable to the burden of the tax Borne imports. In terms of administration, to ensure the VAT principle of self-censorship among users, making it easier to work administration tax, and reduces the possibility of tax evasion, if he wanted money or performer resource services reduce the amount of tax Owed it, it is the interest of who buys the full amount ADRA in the list to be able to purchase through the exercise of Right decides to take advantage of the tax paid. On the other hand, if an adult buyer when preparing lists the value of the tax Paid, the interest of the Muslims of funds or performer registration services tax to avoid paying the true amount is greater than Amount of tax actually owed them.(19)

\section{Disadvantages Of Vat}

There are several disadvantages associated with the application of VAT to impose anti mentions this tax and take of this causes a cause for opposing the imposition of this tax, whether this objection in a phased manner exponent door and under certain conditions or permanently, and researcher when referring to those disadvantages are not aimed at the development of the obstacles to the implementation of this tax in Iraq, But the goal of the quest to reduce the effects of such disadvantages, or is accompanied by, or a result of the negative aspects in the future and follows Review of these disadvantages, Treatment of capital goods, in most countries of the world are retrieved VAT by the party that has Paid to encourage investment in capital, and because spending on investment goods do not count in consuming the proper sense, However, other countries such as China and Brazil do not return on capital goods, and other countries are Returns the value of the tax on capital goods gradual and equal to the value of consumption or the demise of the capital, and lead. For the lack of direction of economic units to invest in capital, of course, so dangerous, especially in a society Such as Iraq, which it may resort facilities and means of production to labor-intensive because of the state of economic development after the change Witnessed in Iraq and opening up of the market economy, and modern companies or those seeking to expand may find themselves Pay more tax, which sells goods (i.e. if revenues less than Egypt and her death), which will be signed in a liquidity crisis. Even in countries which returns all or some of the tax on capital goods may find this modern companies or Dilated themselves facing the same crisis, because the waiting retrieve taxes from the government, which usually take For a long time Favoring imports at the expense of local industries often taken at the VAT they Favoring imports because they impose the tax by one, and discriminate against the local industries because they are subject Tax at each stage of production, and the recovery of taxes on intermediate goods often takes time and effort.(20)

It is also drawbacks it may lead to the establishment of vertical and horizontal integration in the industry for the purposes of tax evasion, Which leads to inefficiencies in production and perhaps monopoly.

It is essential for the disadvantages of this tax it is somewhat complicated in practice, and requires the presence of advanced accounting system what kind of businesses and institutions, and who will bear the brunt of the companies are well-organized while you can Small and medium enterprises to easily evasion of these taxes.

\section{Obstacles To The Application Of The Vat System}

Noted below in a range of obstacles facing the implementation of VAT, is not intended that the impossibility applied or put difficulties before they are applied in Iraq, but the aim of the boot to the implementation process and to try to overcome those Obstacles or minimize the negative effects of expected her, The difficulty of the application in the Regions, The success achieved by the value-added tax cases state Simple installation Political (State Standard) led to wonder about the possibility of her application at the level of the non-central or federal, While allowing regions to the extent of independence in the design of the tax, but the challenges are many in this aspect.

The most important no limits Markup between regions, as well as the problems of the tax deductibility across regions, in addition to the possibility of determining the rate of one for the value-added tax applied to sales intermediary between jurisdictions in the system Federal, and so it is not good in the case of federal states as well as in the case of States that are associated economic union, in the case of States, the federal tax on consumption can be imposed from BC, but the government and the revenue is distributed by certain provinces or territories of different.

Restrictions on the movement of goods and services, it is known that in Iraq not to hard limits or restrictions on the movement of goods and services between provinces or territory, so the percentage of the distribution of shares of local governments faces the problem of how will get all the local government of revenue, for example, if the seller of the provinces of the Kurdistan region, which Bought the goods or service from one of the provinces in southern Iraq, and that the deal has been in the center of Iraq Suppose in Baghdad, is that this deal recorded in the province of the Kurdistan region or the province in which South or those in the middle (of Baghdad), and this will increase the complexity of this case is that the problem of Integrated 
Industries, which has all of them in a different province, and examples of the gas which is produced in the provinces. South and consumed in the middle or the West, and the cement industry, or bricks or fertilizers, and other chemical products . The problem of agents, Foreign: other obstacles to the application of the VAT system, is the issue of agents Trade, it is well known that for most commercial goods in Iraq, and the most delicious Durable Goods Trade Agents, Sole, In many cases, this agent across the country, here's what would have on the conversion in stock From branch to another, or to resort to holding long positions or issue lists somewhere without the other, which will double the size of the Sales in place and reducing sales elsewhere. Administrative difficulties: other obstacles are administrative difficulties which are distributed between the central administration Or what is called the federal government and local governments, and which will be subjected to these problems, such as evasion Tax or intent in issuing documents are representative of the movement of trade between provinces or territory, and because governments Local vary in terms of its administrative capacity, the heaviest burden will fall on the regions and provinces that have systems Administrative advanced, while the Tekirdag provinces and other regions revenues without efforts interview.

Application problems with neighboring countries, There is another major obstacle in Iraq when applying the VAT system,And is this obstacle problem with neighboring countries and that depends completely on the process of trade, which is associated With Iraq, a private commercial agreements, these countries did not apply the value-added tax, and these countries Iran Syria and the Arab Gulf countries, as this will have an impact upon the adoption of inputs for local industries At a time when other companies which rely on input from the inside, and how to retrieve the value-added tax or Production is carried out without paying tax, and it becomes more complicated when there are " border trade " with countries Neighbors from which to buy goods and get re- taxable its then enter it again and sold at market price Without tax.

\section{Audit The Vat}

The audit tool is one of the serious weaknesses in the management of value-added tax, as referred to in the reports On the application of VAT in many countries, especially developing and transition countries, and prove to them that Many developing countries in the past ten to fifteen years do not yet have effective programs to audit, Without an effective audit deteriorating level of compliance to VAT, and weaken the credibility of the tax administration, and so on The strengthening of the audit process represents a major challenge, and can meet the challenge of designing an audit program arbitrator And integrated, as the program of this type represents a critical element in reducing fraud and evasion of VAT Added, the evasion is double when submitting lists of forged and claim to deduct tax for purchases is due Deductible, and stems the importance of auditing for VAT, or because the scammers are potential invaders The existence of a deterrent if they knew that there is a reasonable possibility that the discovery and exposure as ordered we signed under penalty of punishment, which Affects also helps them in that evasion and fraud.(21)

\section{How Does Vat Work}

It is accounted for and paid at all stages of the supply of taxable products and the provision of services. all supplies of goods and provision of services within Iraq by a taxable person in the course of conducting economic activities will be subject to vat. the import of goods will be subject to vat. tax paid on inputs (purchases/ expenses) is credited against taxes collected on outputs (sales). The export of goods from Iraq will be zero-rated. as a result, tax paid on inputs is refunded, making goods produced in Iraq more competitive internationally.(7)

\section{Value Added Tax Law For Iraq}

The law should be based upon the invoice or credit method of levying vat, as follows: an invoice issued during a transaction reflects the value of the goods/service, the tax and the registration number of the registered person issuing the invoice; and on the strength of the invoice, the recipient of the supply (input) claims a credit for the tax paid, against the tax collected on outputs.(5)

\section{Research Findings And Data Analysis}

And discusses the analysis and interpretation of data in this paragraph. This paragraph also talks about the methods used to analyze the data of this study. Was the first analysis that was conducted frequency statistics of personal information demographics of the respondents, followed by inferential statistical measurement which is the correlation of the variables and finally multiple regressions. The data were collected using a questionnaire, e-mail and personal interviews. Of the (110) questionnaires, and received (95) responses out of ( 89 ) of these responses were found to be complete. These were used in the analysis of (100) responses. The interpretation of the results is also discussed in this paragraph. 


\subsection{Demographic Data}

Profile of Respondents
\begin{tabular}{|c|c|c|c|}
\hline & Type of work & Number & Percent \\
\hline 1 & Academic & 30 & $39 \%$ \\
\hline 2 & officer & 25 & $27 \%$ \\
\hline 3 & Financier & 20 & $23 \%$ \\
\hline 4 & Private sector & 14 & $11 \%$ \\
\hline & Total & 89 & $100 \%$ \\
\hline
\end{tabular}

Shows the table where it appear that $39 \%$ from academic of Universities and $50 \%$ of experts and practitioners in financial circles and $11 \%$ of private sector who represent the taxpayers to pay the tax are members of the union of businessmen and chambers of commerce and industry.

\subsection{The application of VAT}

Table ( 1 )

\begin{tabular}{|c|l|c|c|}
\hline & Where is the implementation of the value-added tax? & Number & Percent \\
\hline 1 & $\begin{array}{l}\text { Implemented by the central government and the distribution of revenues to } \\
\text { the regions. }\end{array}$ & 50 & $60 \%$ \\
\hline 2 & Implemented by the provincial and local governments. & 15 & $9 \%$ \\
\hline 3 & Implemented by the central government only spent centrally. & 24 & $31 \%$ \\
\hline & Total & 89 & $100 \%$ \\
\hline
\end{tabular}

Shows the table ( 1 ) The majority of respondents with the direction of the central imposition and implementation of value-added tax, but how the distribution of the revenue or spending $60 \%$ with spending the central revenue, while $31 \%$ agree with the distribution of revenue regional or local governments either $9 \%$ of the sample on Implemented by the provincial and local governments.

\subsection{The success or failure of the VAT}

Table ( 2 )

\begin{tabular}{|l|l|r|r|}
\hline & The success or failure VAT & Number & Percent \\
\hline 1 & Do you think that the imposition of VAT in Iraq successful? & 68 & $67 \%$ \\
\hline 2 & Do you think that the imposition of VAT in Iraq will not succeed? & 21 & $33 \%$ \\
\hline & Total & 89 & $100 \%$ \\
\hline
\end{tabular}

Shows the table ( 2 ) After taking the sample results about whether the success or failure of the imposition of VAT concluded that $67 \%$ of respondents believe the success of the application of VAT. But $33 \%$ of respondents do not believe the imposition of VAT implementation successful give my promise to him the current situation and tax evasion, among others.

\subsection{VAT and Accounting Records}

Table ( 3 )

\begin{tabular}{|c|l|r|c|}
\hline & The record-keeping at the imposition of VAT achieve & Number & Percent \\
\hline 1 & The possibility of the implementation of VAT and easily streamline & 45 & $54 \%$ \\
\hline 2 & Activation of the relationship between the accounting and tax & 15 & $20 \%$ \\
\hline 3 & $\begin{array}{l}\text { Integration in the exchange of information in order to assist in the imposition } \\
\text { and collection of other taxes }\end{array}$ & 29 & $26 \%$ \\
\hline & Total & 89 & $100 \%$ \\
\hline
\end{tabular}

Shows the table (3) Special maintenance of records when the imposition of VAT. Said that a large proportion of those who distributed them leaves resolution of the possibility of achieving fruitful interaction at irregular taxpayers to pay the tax and the maintenance of books and accounting records were whispered a 54\%. While the percentage of supporters to achieve integration and the possibility of obtaining information contributes in determining the different taxes for similar projects to a minimum and by only $20 \%$. Has shown $26 \%$ of respondents agreeing on the importance of activating the relationship between the accounting and the status of evolution in which the theoretical and practical applications of side tax theory as ideas, legislative and practical applications of the other side. The results of the analysis follows:-

\begin{tabular}{|c|c|c|c|c|c|}
\hline $\mathrm{Q}$ & Arithmetic mean & Standard deviation & Answer severity & $\begin{array}{c}\text { Coefficient of } \\
\text { variation }\end{array}$ & $\begin{array}{c}\mathrm{T}-\text { Test } \\
\mathrm{P}<0.05\end{array}$ \\
\hline 1 & 2.32 & 21.0713 & 3.775 & 4.843979 & 2.055 \\
\hline 2 & 2.55 & 24.000 & 5 & 5 & 1.632 \\
\hline 3 & 2.38 & 15.1327 & 4.15 & 3.381 & 2.861 \\
\hline
\end{tabular}

The higher the value of the arithmetic average of the values contained in the Likert scale is triple the number (3). It is the arithmetic mean of the values of Note in the table note that the highest value of the average arithmetic ( 2.55 ) It is less than the arithmetic average supposed. The average standard deviation equal to ( 21.32733 ) It is close to the value of the standard deviation of the average. As for the unit or the severity of the tested sample stuck to the content of the questions (answer intensity) has been stationed second question and a sample agreement fully. 


\section{Conclusions}

1- Iraq is one of the oldest countries in the world in the enactment of laws and tax legislation.

2- The Iraqi tax system suffers from under-development with its inability to provide the necessary financial revenue to the requirements of public spending as well as the inability to catch up with the economic and social developments in the country.

3- Iraqi characterized the tax system neutral in the sense that no role in the implementation of the state policy and the economic impact of the economic activity of the year.

4- There are a number of obstacles preventing compliance taxpayer to pay the tax in Iraq, and the lack of commitment to voluntarily disclose income earned him and the volume of financial transactions, which exercised, as well as non-submission of tax returns and tax return on time, and these obstacles, and there are cases of abuse and lack of justice, as well as the weakness of tax awareness programs, and the lack of consensus and harmony in the penal system, as well as administrative corruption.

5- Not up to pay the tax charge in Iraq awareness to the degree to which understands the importance of a balance between rights and duties, and to pay the voluntary tax compliance, and due to the lack of understanding of the national dimension of the tax.

6- Requires the application of VAT in Iraq, have assigned subject to the tax payers, whether natural or legal persons, a good business accounting systems including menus and records in accordance with the official forms, and bound by the bookkeeping and records for tax purposes.

7- There is agreement on the importance of the unified rate when the imposition of VAT. The agency responsible for the administration of VAT, it is better to be part of the GCT, and that the motive rationale for this agreement due to the GCT has the potential administrative and human cadres makes them more able to implement such a tax.

\section{Recommendations}

1- Work to bring tax reforms integrated and coordinated suit, especially with the economic reforms in Iraq, and is mainly reform and amendment of legislation and laws, tax and work to make it fit in with the need, current economic realities by making these laws are clear and easy to understand with the issuance of new laws on the activities of important economic Activity such as mobile phone companies.

2- The application of the law to impose VAT form are improving the efficiency of taxation and achieve the goals and objectives, requires that application based on the existence of tax administration efficient and able to understand the provisions of the law and the mechanisms for its implementation, and requires that the regularity of the staff at the GCT and its subsidiaries, in session training leading up to the issuance of the new law and inflict.

3- Motivate taxpayers to pay tax on the performance of their duty tax according to the provisions of the law on a voluntary basis through tax them, and should not be limited to taxpayers to pay the tax, and that extends to the sectors and state institutions and pain combines all, from the importance of the national dimension of the tax, and that their performance is a chore nationally and ethically based on the principle of social solidarity, and that the entire community is responsible for ensuring the performance of this duty by each of the consequent, and that this requires the concerted efforts of religious organizations SOCIAL consciousness, academic and professional, in order to raise awareness of tax and educate the community about the importance of social solidarity, and the importance of tax and objectives in achieving development and public welfare and economic development.

4- Management reforms of the Public Authority for taxes to avoid the administrative barriers that hinder the development of the tax and its role in the economic policy of the state.

5- Tax awareness among the citizens and the definition of the importance of VAT and its role in the provision of public services.

\section{References}

[1]. McLure, C. 2000. Implementing Subnational Value Added Taxes on Internal Trade: The Compensating Vat (CVAT). International Tax and Public Finance 7, 723-40.

[2]. Auerbach, A.J. and Gordon, R.H. 2002. Taxation of Financial Services under a Vat. American Economic Review 92, 411-16.

[3]. Aujean, M., Peter Jenkins, and Satya Poddar. 1999. "A New Approach to Application of VAT to Public Sector Bodies." In International VAT Monitor, Vol. 10 (No. 4).

[4]. A tax net full of holes' 2006, The Economist, 11 May 2006, 379(8477), p. 87.

[5]. Ahmad, E 2010, = Design of a VAT for the GCC common market', in E Ahmad and A Al Faris (Eds.), Fiscal Reforms in the Middle East. VAT in the Gulf Cooperation Council, Edward Elgar Publishing, Northampton, MA, pp. 1-24.

[6]. Morse, S C 2011, How Australia got a VAT', The VAT Reader. retrieved from http://www.taxanalysts.com/www/freefiles.nsf/Files/MORSE 23.pdf/\$file/MORSE-23.pdf.

[7]. OECD 2006, Consumption tax trends - VAT/GST and excise rates, trends and administration issues 2006 ed., OECD Publishing, doi: $10.1787 / \mathrm{ctt}-2006$-en.

[8]. OECD 2009, _Developments in VAT Compliance Management in Selected Countries', Information Note August 2009 OECD Forum on Tax Administration: Compliance Sub-Group. 
[9]. TEERA, J. M. (2001). "Tax performance. A comparative study”. University of Bath, Department of Economics.

[10]. Auerbach, A., and R. Gordon (2002). "Taxation of Financial Services Under a VAT."' American Economic Review 92(2), 411416.

[11]. Campodonico, Jorge-Baca; De Mello, Luiz \& Kirilenko, Andrei (2006). "The Rates and Revenues of Bank Transaction Taxes", OECD Working Paper $n^{\circ}$ 494, Paris, OECD, June.

[12]. Alm, James and Jorge Martinez-Vazquez (2007), "Tax Morale and Tax Evasion in Latin America", International Studies Program Working Paper 07-32, Andrew Young School of Policy Studies, Georgia State University.

[13]. Desai, Mihir A., and James Hines Jr. 2002. Value Added Taxes and International Trade: The Evidence. Paper presented at the International Tax Policy Forum/Tax Policy Center Conference on "Tax Systems and International Trade" on December 9, 2002 at the Brookings Institution (Washington D.C.).

[14]. http://www.wordwendang.com/en/word_economy/0531/48383.html

[15]. Fourth ITD Global Conference: Tax and Inequality, New Delhi, 7-9 December 2011

[16]. Simon Games, "Tax Compliance, self -assessment and Tax Administration", University of Exeter, Clinton Alley, New Zealand, 2006, p 78 .

[17]. Slemrod, J., and S. Yitzhaki (2001), "Integrating expenditure and tax decisions: the marginal cost of funds and the marginal benefit of projects", National Tax Journal 54(2): 189-201.

[18]. Desai, Mihir A., and James Hines Jr. 2002. Value Added Taxes and International Trade: The Evidence. Paper presented at the International Tax Policy Forum/Tax Policy Center Conference on "Tax Systems and International Trade" on December 9, 2002 at the Brookings Institution (Washington D.C.).

[19]. Shaoul, J. "The Private Finance Initiative of the Public funding of Private Profit?"

[20]. In C. Greve and Hodge (eds) The Challenge of Public Private Partnerships Learning from International Experience, Edward Elgar,London,2005, p 92.

[21]. James Bickley, "Value - Added Tax as a New Revenue Source, Congressional Research Service" Public Finance Review, VOL.25,No.3, U.S.A. 2005, p 64.

[22]. Tait, A. 1988. Value Added Tax: International Practice and Problems. Chapters 2. Washington D.C.: IMF. 